\title{
The Roles of Time, Place, Value and Relationships in Collocated Photo Sharing with Camera Phones
}

\author{
Hanna Stelmaszewska \\ Interaction Design Centre \\ Middlesex University \\ Hendon, The Burroughs \\ London NW4 4BG \\ +44(0)2084114650 \\ h.stelmaszewska@mdx.ac.uk
}

\author{
Bob Fields \\ Interaction Design Centre \\ Middlesex University \\ Hendon, The Burroughs \\ London NW4 4BG \\ $+44(0) 2084112272$ \\ b.fields@mdx.acuk
}

\author{
Ann Blandford \\ UCL Interaction Design Centre \\ University College London \\ RemaxHouse, 31-32 Alfred Place \\ London WC1E 7DP \\ +44(0)20 76795288 \\ a.blandford@ucl.ac.uk
}

\begin{abstract}
Photo sharing on camera phones is becoming a common way to maintain closeness and relationships with friends and family. How people share their photos in collocated settings using camera phones, with whom they share, and what factors influence their sharing experience were the themes explored in this study. Results showed that people exhibit different photo sharing behaviour depending on who they share photos with, where the sharing takes place and what value a picture represents to its owner.

In this paper, we will explain what triggers the photo sharing activity and how the sharing takes place depending on who photos are shared with and where they are shared (e.g. restaurant, pub, home). The sharing experience is hindered by the difficulty of controlling which photographs are made available to particular people; sharing with a group of people at once; and ensuring appropriate privacy measures. These findings highlight requirements for novel mechanisms for organising, sharing, and displaying photos as well as provide a better understanding of photo sharing behaviour using camera phones in collocated settings.
\end{abstract}

\section{Categories and Subject Descriptors}

H5.m. Information interfaces and presentation (e.g., HCI): Miscellaneous.

\section{General Terms}

Design, Theory

\section{Keywords}

Photo sharing, personal photography, social interaction, camera phone, sharing behaviour, place, user experience

\section{INTRODUCTION}

Photography in some ways has affected almost everyone: those who take photographs, those who view them and those who are captured on them. It is a way of recording important events, capturing beautiful scenery or amusing events and simply documenting our lives. Photographs are important artifacts for their owners and they are very often used as a means of social interaction $[10,11,23,27,29]$. Photo

\footnotetext{
(C) The Author 2008
}

Published by the British Computer Society sharing as a way of social and collaborative activity has been a topic for discussion by some researchers. Frohlich et al. [6] suggest that viewing photo albums with pictures from the last holiday, family weddings, birthday parties or other family events during gatherings of family or friends is not only a part of the entertainment but also something that creates bonding between the people involved. Others, like [3], imply that sharing pictures with friends and family is the most commonly enjoyable experience, allowing us to tell a story or make people smile.

With the advent of mobile technologies including camera phones, people increasingly use them to facilitate their social life outside the work environment. The popularity of using camera phones is further testimony to the importance of the new ways camera phones have been used to change the way people communicate and pursue social interaction via sharing of digital photos.

The phenomenon of photo sharing behaviour has been has received much attention in recent years $[1,10,20,23,28]$, with many researchers focusing on using different media for sharing purposes.

Photos taken on camera phones may be shared through the MMS services, email, posted on websites or if in co-located environment they may be Bluetooth-ed to other phones. Much research in the area of photo sharing has focused on people's social uses and practices of digital photos $[1,10$, $18,28]$. However, how people share their digital photos in collocated settings has been neglected.

Photo sharing is a social and collaborative activity. However, people behave differently when sharing a photograph album in the comfort of their home or sitting in the restaurant waiting to be served [12, 23, 24].

Research has shown $[2,32]$ that face-to-face sharing is a common practice, however there is not much work done to explore this kind of sharing using camera phones. Thus investigating issues relating to photo sharing in different collocated settings might bring a new knowledge to researchers as well as designers helping them to understand people's needs when sharing on camera phones is involved.

To fill the gap in current knowledge within the field this study is exploring issues related to the sharing of mobile photos (i.e. those captured and shared through mobile phones) with the focus on how, when, where, who with, and why people share photos in collocated settings.

\section{RELATED WORK}

The uses of digital photography have been addressed by many $[1,5,11,12,16,23,29]$ but little work has considered the photo sharing in collocated setting using camera phones. This section will provide background research into photo sharing practices, which will help in positioning this study within these areas of research. 
Digital photos in personal collections are typically taken by the collection owner, or by their friends and family and shared using different mediums such as: email, sharing websites (Flickr, KodakGallery, Yahoo), Bluetooth, or MMS.

According to [2] collocated photo sharing is an integral part of face-to-face communication. It has also been suggested that informal communication in close proximity is a key factor in communications between people [8, 9, 32]. We argue that photo sharing is a catalyst, which shapes social interaction and it changes depending on where sharing takes place, who it is shared with and most of all what the content of the shared photo is.

Photos are about people and their stories $[1,6]$. In many cases, they serve as memory triggers or simply tell a story, which will be different for different audiences. Having the same set of photos people tell a different story [5], emphasising different aspects when showing the photos to one's mother as opposed to a friend or an acquaintance.

The relevance of social relations to the uses of photographs was discussed by researchers like [26, 29]. The former claims that pictures "strengthen the relation between the user and people being photographed" (p. 308). The latter identified five distinct social uses of personal photos. These are: creating and maintaining social relationships, constructing personal and group memory, self-presentation, selfexpression and functional communication with self and others. The recent study of [30] explored the uses of images in social interaction using the remote public on-line system called Flickr. The researchers found that people post their pictures on Flickr to create a chronology of images for memory, identity and narrative, maintain relationships, for self-representation, and self-expression. Although the popularity of this kind of systems is continuously increasing, this study did not explore remote photo sharing practices; instead it investigated the sharing photos with people in the vicinity using camera phones.

How people use their camera phones focusing on the range and diversity of use to understand why people capture images on camera phones was investigated by [10]. Moreover, [10] elucidated the characteristics and context of use of those images for different purposes. A six-part taxonomy, proposed by them, describes the intentions behind the use of camera phone images. These include: affective intentions enriching a mutual experience, communication with absent friends or family and personal reflection or reminiscing; functional intentions supporting different tasks: mutual, remote and personal.

Others, such as $[14,20,22,27,31]$ focused on teenagers using their phones for social practices. Taylor and Harper [27] analyse teenagers' phone-related practices as a form of 'gift-giving' ritual. Such practices are seen to shape the way teenagers understand and use their mobile phones. The 'giftgiving' practices included sharing certain text messages, call-credits and even the mobile phones themselves. All these practices establish and cement allegiances and sustain rivalries.

A similar view was taken by Scifo [22]; he claimed that taking photographs on camera phones and using MMS allows users (youngsters) to identify themselves within a social group and will intensify communication within that community. Moreover, with MMS people allow others to access places, individual and social situations, and emotions captured on the phone. It was also claimed by [22] that camera phone pictures extend one's experience and memory that is portable in a visual and shareable form.

Researchers such as Okabe [19] suggest that camera phone users perceive images that can be used to tell stories as 'photo-worthy'. Speaking while sharing photos is not only natural but is also socially expected and the story is told not just with the photos but also about the photos $[3,15]$.

The purpose of the study reported here was to gain a better understanding of people's photo sharing behaviour occurring in various places and how the properties of place can facilitate different sharing behaviour. Furthermore, to study how social affordances together with the affordances of place and technology, as well as the value of photos, shape the experience of sharing. In this study the sharing of camera phone photos means any activity that involves showing, viewing and transferring pictures captured on camera phones.

\section{DESCRIPTION OF THE STUDY}

The study presented here is an extension of our earlier work $[23,24]$, which identified social uses and practices of camera phones users occurring in co-located settings. Three distinct practices were observed including 'sharing a moment now', 'sharing a moment later', and using photos to initiate social interaction with strangers. Moreover, the findings suggested that peoples' sharing behaviour and use of camera phones changes depending on the place in which sharing occurs (e.g. pub, restaurant, park, home). However, the earlier studies did not explore the details of the relationship between place and practices.

The aim of the study reported here was to investigate the photo sharing practices occurring in different places not photo taking practices and their life cycle. Hence the findings discuss only issues related to the collocated sharing activity. Although the study did not explore cultural dependencies, a range of different cultures is represented in the group sample (e.g. British, Russian, Saudi Arabian, South African, Ecuadorian, and Indian). All nonBritish participants have been living in the UK for at least 3 years.

Semi-structured in-depth interviews, lasting between 35 and 55 minutes, were used to identify issues in question. The interview format allowed participants to introduce relevant new issues to the discussion. They were recorded and transcribed. Interviews were conducted with 11 people, adults, who regularly use a camera phone and share the photographs they take with others. Table 1 shows their details.

Participants included $\mathrm{PhD}$ students, and IT workers and other professionals (e.g. engineering, photography, and business). Participants were asked to show the researcher a number (around 5-7) of their photos or video clips taken at different places and talk about the circumstances of taking and sharing. Utilising this type of technique helps in stimulating participants' memories of events, places and situations that were captured by a particular photo or a video $[10,11]$.

The core questions were:

1. What a particular photo shows, where it was taken and why?

2. Who the photo was shared with and what happened during the photo sharing activity?

3. Where the photo was shared (e.g. home, restaurant, pub) and how?

4. When the photo was shared: at the time of taking it or later?

5. What was the experience of sharing photos like? 
Table 1 Description of participants

\begin{tabular}{|c|c|c|c|c|}
\hline No & Pseudonym & Age group & $\begin{array}{l}\text { Professional } \\
\text { background }\end{array}$ & $\begin{array}{l}\text { Camera } \\
\text { phone } \\
\text { experience } \\
\text { (years) }\end{array}$ \\
\hline 1 & Lee & $20-25$ & IT Professional & $>2$ \\
\hline 2 & Gitta & $26-30$ & $\mathrm{PhD}$ Student & $1-2$ \\
\hline 3 & Nadia & $26-30$ & $\mathrm{PhD}$ Student & $>2$ \\
\hline 4 & Sami & $26-30$ & PhD Student & $>2$ \\
\hline 5 & Bob & $31-35$ & $\begin{array}{l}\text { Other } \\
\text { Professional }\end{array}$ & $>2$ \\
\hline 6 & Juliet & $31-35$ & IT Professional & $0.5-1$ \\
\hline 7 & Alex & $41-45$ & IT Professional & $1-2$ \\
\hline 8 & George & $41-45$ & IT Professional & $>2$ \\
\hline 9 & Nina & $46-50$ & $\begin{array}{l}\text { Self-employed } \\
\text { Professional }\end{array}$ & $1-2$ \\
\hline 10 & Stan & $46-50$ & Lecturer & $1-2$ \\
\hline 11 & Ron & $51-55$ & $\begin{array}{l}\text { Self-employed } \\
\text { Professional }\end{array}$ & $>2$ \\
\hline
\end{tabular}

As the data gathered was of a qualitative nature and the aim was to build a theory of photo sharing behaviour of camera phone users that emerged from the data, a Grounded Theory approach was applied to fulfil this requirement. The data collection and analysis occurred in parallel because it allows for 'theoretical sampling on the basis of emerging concepts' and it 'enables validation of concepts and hypotheses as these are being developed' [25]. Data from the study was analyzed by first, coding it (open coding) that identified concepts pertaining to similar phenomena (categories), followed by axial coding, which identified the high level phenomena (e.g. events, activities) and finally the analysis was elaborated and interpreted in the selective coding stage that gave the outline of the photo sharing behaviour of camera phone users.

All the names of participants have been changed to maintain their anonymity.

\section{PHOTO SHARING BEHAVIOUR}

Three main factors were identified that appeared to shape the behaviour of people when photo sharing using camera phones. Those were: categories of people (relationship between people involved in sharing activity: friends, family, and others), place where sharing occurs and the value of photos. The value of the photo (e.g. social, personal, or spatio-temporal) determines who the photo is shared with, as well as how (e.g. pass the phone, hold the phone, Bluetooth photos between phones) and where the sharing will take place (e.g. pub or house).

However, the issues related to the motivations behind sharing is also important to obtain the whole picture of when, why, what, where and how people share photos and what influences they experience.

The following sections will discuss issues related to: (1) the triggers for photo sharing; (2) the values of photos, which determine who they are shared with; (3) the social affordances that provide the accounts for different sharing behaviour when sharing with different groups of people; and finally (4) the affordances of place, which shapes the sharing behaviour.

\subsection{Triggers for sharing}

People share pictures during different activities: eating out, clubbing, social gatherings with either family or friends, or just when they see each other. Three different triggers for sharing were identified: motivational sharing, contextual sharing and ad hoc sharing.

\subsubsection{Motivational sharing}

The intention to share is motivated when taking a particular photo. A friend who appreciates cars will be interested in a picture of a Batman car or a group of football fans will appreciate a picture of a new stadium. So when a situation happen people take a shot thinking 'I saw this and thought you might like it'. Such pictures would be shared as soon as an opportunity arises.

'That's just a friendly cat. I haven't shared it with anyone yet but there is a person that I will be seeing later in a year or so err... I'll show it to her because I know that she likes this cat and it will please her to see this photo. (Ron) (Figure 1)

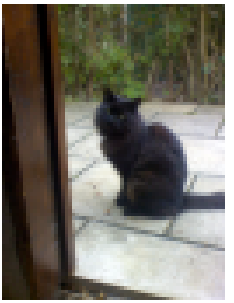

Figure 1 Cat sitting on the pavement

\subsubsection{Contextual sharing}

Very often the photo sharing activity is driven by the topic of a conversation. People usually take an opportunity to share photos either taken during their holidays, showing their loved once, funny situations or something that they are proud of when a situation arises.

'...If you are with a group of friends err... unless the conversation arise you wouldn't say: 'Let's look at pictures'. (Ron)

'It's just err... people ... it's a visual conversation and if anyone says: How is your little boy? And I'd be like: Oh, I just took a photo of him last week and then I'd show the photo.' (Bob).

\subsubsection{Ad hoc sharing}

However, sharing photos is not always triggered by the context of a conversation or a pre-planned activity as in the case of motivational sharing. It was reported that sometimes people share funny or silly pictures, without being prompted by others to do so, which they had received from others or downloaded from the Internet just because they think the pictures will bring a smile to people's faces (Figure 2). Ron's comments support this view:

'Unless there is something, you specifically want to show to someone. Sometime you have a funny picture and you see someone and the first thing is: Have you seen this? And then you Bluetooth it across to them'. 


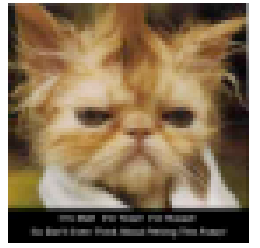

Figure 2 Funny picture shared on the owner's initiative

\subsection{Value of photos}

It transpired from the data that photos have different values to those who share them. Those values are socially or personally oriented, or they relate to the time of sharing. The value assigned to a particular photo determines the life span of it and who is shared with.

\subsubsection{Social value}

The social value of photos, in terms of enabling people with similar interests to share them, has been highlighted in the online context by [16]. In our study, we found that one motivation for sharing pictures with friends is for creating and maintaining social relations, though this is done selectively.

Participants in this study reported that some pictures had been taken in order to share later (this links to the spatiotemporal value - see 4.2.3.2) with friends who have common interests and belong to the same social interest group. Here is an extract from the interview with Sami supporting this claim:

'... I was at Leicester Square ... there was a premier of the Batman film and I took a picture of the car ...I saw the car and it was like, a cool car and I came to the office and I showed it to Simon ... I know that he is into this kind of guy stuff...

For instance, a picture from a specific concert showed to a person not interested in this kind of performance or music will not have the same impact on the experience as a person who is a great fan of a specific artist.

'Some of my friends are artists and maybe I'll show them the photo of the 'Gremlin' but at the same time I'll show the photo when I was at the concert ... beautiful colours ... maybe artists can be inspired by these photos'. (Nadia)

'My friend, he's crazy about motorbikes so when I did the exhibition in Alexandra Palace [a place in London], I just took this photo of a Harley Davidson ... I showed it to him later.' (Nina) (Figure 3)

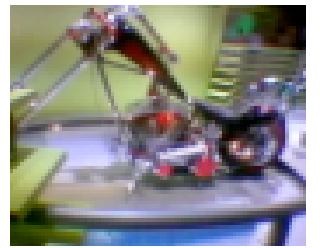

Figure 3 Harley Davidson - picture shared with Harley Davidson enthusiast

\subsubsection{Personal value}

Another value, this time more of a personal and sentimental value, can be added to a photo when there is a strong connection between the subject of the photo and the photo owner. The personal value dictates the life span of the photo (this links to the spatio-temporal value of photos - section 4.2.3.1), its final destination (e.g. an album, a folder on a computer, or a canvas on a wall), and its accessibility to others; that means that this type of photos are usually shared with very close friends or loved ones. However, depending on the content of these pictures they are shared with a different group of people. For example pictures from a funeral are shared with people who attended the ceremony and they knew the deceased as Nadia said:

'Some photos I don't want to show probably err... a few of my friends had been to my Mum's funeral so I do have these photos and I don't want to share them with other people just with those close to me."

Other pictures display the loved ones (e.g. grandmother, child, girlfriend or boyfriend) and are shared with them or friends. They are very valuable for their owners and even when they change camera phones the pictures are always transferred across so they can be viewed and shared when an occasion arises. Sami's comments illustrate this view very well:

'This is the picture ... of my grandmother with my son. So I cherish this picture. ... This was like last year at her place ...err... I took the picture ... I showed to my husband, my cousins, my Mum err ... and now I'm thinking that perhaps I should store it on my computer because it's err... an important picture, I mean for me. It brings some memory ... err... and it's close to my heart.'

People also like to preserve the feelings associated with special occasions, events or precious moments that are captured on pictures taken at the time. When shared they strengthen the relationship between friends and share not only the event but also, and more so, the experience encapsulated in them.

'A couple of years ago I took some pictures of the Christmas trees when I went home and I still have them on my phone... and I showed them to my friends many times and when I think about Christmas I just look at them again, and again and I know that I will never delete them. They bring back beautiful memories and the feeling of home and family and that's great and err...I just want to show my friends how it's like at home. I want to keep them.' (Alex)

'... pictures ... they've got some memories, because she is miles and miles away and I've got this red hat [she was wearing it at the time of this picture being taken] under my pillow [laughing] that ... if I see that ... I look at that red hat ... I really miss her and I look at the photo as well. So I have something real and then have the photo on the phone as well... it takes me back to that situation that I was at ... and it makes me cry. No, not really but you know what I mean. I just like looking at it and showing it to my friends'. (Bob)

This kind of picture usually remains in the owners' collection for a long time and they are often transferred between phones (e.g. from the old phone to the new one) or they are kept on the memory card or other media to preserve them and share them with others for a long time.

\subsubsection{Spatio-Temporal value}

It emerged from the data that there are two important issues when spatio-temporal value of pictures is concerned: one relates to the life span of the picture and the other relates to whether a photo is shared at the time that it is taken or later.

\subsubsection{Life span of pictures}

The life span of photos can be divided into two categories depending on how long the pictures are stored on the camera phone for: short or long life.

The short life of pictures refers to the pictures that are relevant for a limited time only and afterwards they lose their value and are no longer the 'punch line' of the conversation. For example, as explained by Stan a picture of a new Emirates stadium (Figure 4) has its special value until all friends, fans of Arsenal, visit the place. By then the value 
of the picture is changed and it no longer gives its owner a sense of pride from 'been there, seen it'.

'...The one of the pitch was only actually valid until all your friends have been there and see it. And once they've all been there and see it then the photograph had no longer that: 'hey, have you see that? [Yes, I have.] Oh, oh ...' (Stan)

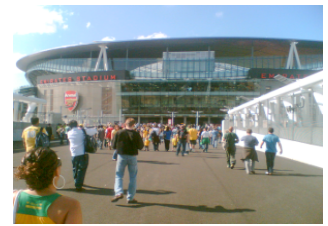

Figure 4 Picture to share with Arsenal fan group

When asked whether pictures are valid just for a certain period of time only or they have a much longer life span, participants commonly responded that some pictures are not only for a moment to appreciate but also they capture nice memories that people like to keep for a long time and return to those pictures from time to time when friends are around.

The long life of pictures is dependant on its content and it might relate to a specific interest of the owner or it captures something important (e.g. a picture of the holiday house abroad) unusual (e.g. Halloween party dress) or beautiful (e.g. Wembley stadium at the sunset) that is worth keeping and sharing with others over and over again.

'The Wembley stadium that's gorgeous photo ... and I had to take it ... I saw this and I said: 'Oh, God! I have to take a photo'. I'm just glad I did it have the phone with me so I could capture the moment ... Still a year later and I'm showing it to people'. (Juliet) (Figure 5)

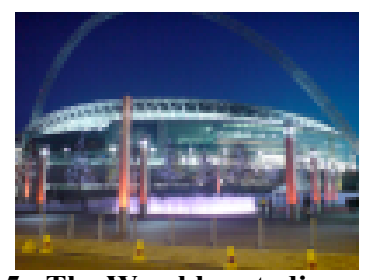

Figure 5 The Wembley stadium at night

Like pictures that have social value assigned to them these kinds of photos are often shared on the camera phones without transferring them across. However, in case of photos capturing funny things or situations (Figure 1 - Cat) often they are Bluetooth-ed to the viewers' phone collections so they can be shared with others not present at the later time. These kinds of pictures usually 'travel' from one person to another as a line for conversation or just to bring a smile to people's faces. The life span of them is usually as long as there is no one left within the circle of friends and family that the owner of the picture would like to share it with.

\subsubsection{Photos shared 'now' or 'later'}

Sharing activity is structured and planned in time but the plans for sharing are often formulated at the time of taking pictures, which was discussed in the 'Motivational sharing' section. There are different reasons for taking pictures: one is to share them with friends who have common interest (this links to the Social value of photos), another is to share them with our loved ones with an intention to show them something that they are interested in (link to a social value), or yet another is to share photos that capture something special (e.g. a place, an event) that the owner of the photo would like to share with friends or family (link to a personal value).

As mentioned earlier sharing photos is usually accompanied with a narrative story behind the photos, which conjure memories, feelings and emotions and evoke senses associated with the event or places that were photographed. It does not stop here; they allow the viewer to 'travel' to the place and space captured on those photos and experience what the owner of the photo experienced at the time.

I mean if you just show a picture there is only a picture but I like to say where it was taken and what happened, etc. and I love doing it because every time I say something I go back to that very place and share those precious memories from all these places err... yeah. And whoever I share them with, can just imagine what was like up there. It's like teleportation [laughing]. I like telling stories, yeah'. (Alex)

The spatio-temporal value of the photos is strongly linked to other values (i.e. social, personal) and cannot be viewed as a totally separate entity.

\subsection{Social affordances}

Most of the time, when discussing what influences photo sharing experiences participants commented that it is people who create the experience. It emerged from the data that the relationships between people determined what type of photos they shared with family, friends and others as well as how the sharing took place.

\subsubsection{Sharing with family}

In line with [3] and [16] our participants reported sharing pictures primarily within the existing social network of friends and family. However, the content of a photograph was a key determinant of whom it would be shared with, the emphasis being on its suitability when sharing between family members. Usually, these photos contained family members, family events, or holidays, rather then pictures taken with friends during the parties or outings together. This echos the findings of [16] who found that the 'Kodak Culture' group was very protective of who they share photos with, mostly with family, and the photos were mostly of themselves.

Comments from one of the participants are representative of others who took part in this study:

'...The kind of pictures that come out [laughing] [referring to pictures taken when with friends], no family. Unless is family then I'll show it to them.' (Nadia)

Typically the sharing happens not only on camera phones but also on other media; these are computers (e.g. desktops or laptops), TV-screens or digital tablets. In addition, sharing is more formal and very often takes place at home during family gatherings, parties or after dinner as a part of the day's reminiscing.

'... with family usually we take a lot of pictures and then at the end of the day when we come back home or even at home just before we go to bed we put them on TV or on the computer and then all of us gather around and watch what pictures we've taken.' (Nadia)

All pictures containing family members, family events, or holidays were viewed regardless of their quantity even though some pictures could be duplicated or cover the same theme extensively.

'... Family members ... they can see all of these pictures. I think other people would be bored with those family pictures.' (Nina)

When sharing photos with family on camera phones people are more reserved. The common behaviour was to give the camera phone to a member of family and show one picture at the time. It appeared that even though the relationship is very close, family members feel respect towards their love ones and do not want to cross the border of their privacy. 
Therefore, they will just view the one selected by the picture owner and return the phone back waiting for the next picture to be shown. Comments from Juliet support this view:

'I'd show them the picture on the phone ... yeah. They would hold my phone but then they give my phone back after every picture.

Another common practice was to hold the phone in front of the viewer and flip through the collection as Nina noted:

'...when we got back home only my son was there and he asked me if I have any pictures from the holiday and I showed them to him... I was holding the phone and went through the pictures and he asked me about where they were taken and ... I was flipping through them.'

\subsubsection{Sharing with friends}

When it comes to sharing pictures with friends, unlike when sharing with family, the sharing is more informal and can happen anywhere. When asked 'Where do you share pictures?' Gitta responded, which is a representative comment of all participants:

'...It doesn't matter, whenever we are. If we are at the rugby game, pub, restaurant ... regardless where ... restaurants, bars or even when we are meeting up in a house of any of us. It would be there',

The common practice is to share them 'on the spot' (immediately after taking pictures) or share later during social gatherings [24]. It was claimed by [10] that the majority of photos are not sent immediately via MMS but rather shared off the handheld screen when people are copresent. The findings from the data show that this kind of behaviour was common during social gatherings with friends.

Pictures shared 'on the spot' and taken 'on the move' are Bluetooth-ed or MMS-ed to others who are present and wish to have them on their camera phones.

'...I am quite used to Bluetooth-ing it to other people ... that's the main way we share... it's a very immediate thing. So like you take a photo, you look at it and then someone can say: 'Can I have it?' and you Bluetooth it. So it's kind of done very quickly. Yeah, I would say that that would be the main way of sharing.' (Stan)

'... actually, I pass the phone and show the pictures and then if they ask me to send it to them I Bluetooth them.' (Gitta)

The same kind of sharing also happens at the later time in the comfort of people's homes when they feel more relaxed and have more time to socialise with friends, which is in line with [20].

'...usually when you are at the person's house having a $B B Q$ and, you know, you say: 'Do you still have these photos?', Oh yeah. And then you share them via Bluetooth because you are more relaxed ... again sitting at the fire and people had all kinds of nice movie clips, ring tones, pictures, you know, different kind of stuff ... we just switch on the Bluetooth and this guy sends to me and I send to him'. (Lee)

The data shows that the common practice is to divide pictures into two collections: public and private. The former refers to the set of pictures that can be openly shared with friends whereas the latter refers to pictures that are 'for my eyes only' (for the owner of the pictures, or selected people only). The common practice in case of protecting private pictures is to transfer them from the camera phone to a computer and then delete them from the phone. By doing so the issues of privacy no longer exists and the sharing experience is not obstructed by the worries of pictures being seen by unwanted people. Others protect their privacy by deleting their private pictures from the camera phones without transferring them to different media (e.g. PC, laptop).

Friends trust each other and one way to demonstrate this is to give camera phones to them without having boundaries as to what they can and cannot view. The kind of pictures shared would include the ones of family, themselves and other common friends with those not present at a specific event just to share the experience with them. However, when sharing family pictures the selection would be limited to only a few best shots to share the experience and avoid being bored with too many of them very often on the same theme.

\subsubsection{Sharing with others}

A different kind of sharing behaviour was reported when showing pictures to others such as: friends of friends, acquaintances, associates, friends' family, or strangers (e.g. at work or during formal gatherings). People tend to guard their phones more, which was illustrated by the way they hold camera phones in front of others. The trust present between friends allowing them to view pictures freely on each other's phones disappears when sharing with 'others'. People are more reserved and would only show one picture at the time without taking any chances that people present would view the whole collection. When asked about this issue one of the participants commented:

'... Others would just see the pictures that I show them. So it's like: 'Look at this picture' ... and they don't go through pictures'. (Sami)

This kind of behaviour is often the result of previous bad experience, which changes peoples' attitude towards photo sharing.

'...you tend to be more careful what you have on your phone. It wasn't like that before but then people started looking at the pictures that I didn't want them to look at them'. (Nadia)

Sharing with strangers occurs very rarely or not at all; this is consistent with the findings about the 'Kodak Culture' group studied by [16] as well as [3]. However, it contradicts the behaviour of the Snaprs group (people using public photo share system) [16], who treats all photos published on Flickr as public and share them with strangers without having any concerns about the privacy of those pictures.

\subsection{Affordances of place}

For participants in this study, sharing is one of the main motivations behind taking pictures. It creates social bonding where people share with intimate others their memorable moments, funny situations, or just reminisce time spent together. The sharing experience, however, does not exist in a vacuum but is a dynamic relationship with other people, places and objects [17].

According to [4] place is more then just a location. It is linked to people and their activities happen in that location creating a complex relationship between place and peoples' action. Places constrain and enable people to perform their activities as well as offer them structural, cultural and social value that shape their actions [21]. The following section will explore the relationship between different places (public, private, and work environment) and people's photo sharing behaviour, which is also dictated by commonly acceptable norms and regulations assigned to those places. 


\subsubsection{Public places}

Public places were described as places where different social activities take place and that are accessible to the general public (e.g. pubs, bars, clubs, restaurants, cafes, tube, museums, galleries, exhibitions, temples, churches, or social clubs).

It appeared from the data that people share photos differently in different public places. Moreover in places such as churches, temples, museums, galleries, or exhibitions, sharing did not occur following norms and regulations that applied to those places. More discussion of this issue is presented in Section 4.4.1.1.

Other public spaces like pubs, restaurants, clubs, places of entertainment and leisure provided a different social context for sharing activities, which is in line with our previous research $[23,24]$. The data illustrates that people more often engage themselves in social interaction using camera phones during gatherings or parties with friends and family, when going out, or during excursions with friends.

'... Normally everybody after dinner would go to the living room and listen to music and I'd show them pictures, (Nadia).

According to [13] when people are collocated, their collaboration is afforded by their unconscious use of the inherent properties of place, body presence, movement, and sensory mechanisms. The data from this study confirms this view. People reported pubs, bars and restaurants to be social places but their sharing behaviour changed depending on where they were. It could be suggested that not only the attributes of a specific place (e.g. sitting arrangement in a restaurant creates more private environment) but also social and cultural characteristics of a place (e.g. bars are for socialising with people, talking and drinking) dictates what sharing behaviour will be applied. For example, in pubs or bars during busy evening hours when the light is poor and the level of noise is high, people tend to share photos with people who are in close proximity so they can talk about particular photos as well as show them. However, if there are many people involved in sharing, the social and cultural characteristic of a place (e.g. noise, crowd, people moving around, which is typical to pubs and bars environment) shape the sharing behaviour, which is passing the camera phone around.

'...if you are sitting next to the person it's fun, you can share it but if there are many people sitting at the table you are just send it across, send the phone across and ask people to take a look at it.' (Nadia)

The narration of photos, which usually accompany the sharing activity, was reported to be more difficult in such environment as participants stated:

'... pubs ... hum. Sometimes is just too noisy you can't talk to people around you so if you show them a picture and you want to tell them story about it it's errr... not always easy ... too noisy and crowded. So there might be a lot going on around and you can't have a good conversation.' (Nina)

'...sometimes there is an intrusion from the outside err ... if you want to tell a story behind this picture, you know, people might not be able to hear you if the place is noisy ... if you want to talk about something then err... the impact of the photograph or discuss the photograph further then errr ... obviously the pubs and clubs might not be the best place to do that (Stan)

People exhibit different sharing behaviour in restaurants. Although restaurants were described by participants as a social place, social interaction took on a different turn in comparison to a vibrant pub or bar atmosphere. It emerged from the data that the ambience of a restaurant makes people feel more at ease to share their photos. The physical structure of a restaurant (e.g. set up tables) where people sit waiting for a meal to be served creates more private like environment and affords sharing photos by passing their phone around:

'...it's a bit different err... you sit at your table and can talk to others and it's $O K$. It's more private then in a pub... people sit and don't walk around that much. It's a place where you eat not socialise much and drink. Well, you do with people sitting at your table so then you can show them pictures and have a good laugh.' (Nadia)

However, participants stated that although a restaurant environment allows them to engage in a sharing activity and pass the phone around, the narrative part of sharing is limited.

'...in the restaurant you are sitting at the table not kind of walking around the place ... it might be more difficult for me to be involved in sharing. Because if I give my phone around I wont be able to do kind of 'oh, look at this' and show people the pictures, yeah. I'll be like more passive because you can't really walk around the table err... it's not that convenient. (Sami)

\subsubsection{Norms, regulations and constraints}

It was reported in the literature that some public spaces are regulated by signage, announcements and by more informal regulations $[7,8,20]$. The former suggest that these regulations are mostly exercised in public transport. [20] claim that people use email rather then voice calls when on trains and subways following 'sharing the same public space' regulations.

However, even though participants claimed that they would share photos anywhere, the data indicates that peoples' photo sharing behaviour is also regulated by the different norms and regulations. In some places (e.g. museums, churches, temples, theatres unless the sharing happened during an interval and was triggered by a conversation) people follow unwritten rules as what is acceptable and not acceptable to do.

'...Probably in museum where they are not expecting too much noise I'd take a picture and then later share it with other people ... in a temple you are not expected to take pictures so you take whatever you can but you don't share in immediately. You don't want to show people that you are taking pictures' (Nadia).

'...In the Church of England you do not get people taking photos at funerals. In weddings, yes. In Baptising, yes. ... so it's an unwritten rule and it is a cultural norm that there are some places that you don't use mobile phones' (Stan)

Participants also mentioned that their sharing activity relates not only to the place it might occur but also the occasion. The sensitivity of the occasion would be a determinant for sharing to take place or not. The most common example is a funeral or a Baptist ceremony where people would not get involved in a sharing activity.

'I think it is not the place, it's rather the occasion ... at the funeral that would be an occasion that I wouldn't show the photographs. These are like unwritten rules, if you like. Err... we took some photographs at Nicolas' Baptist ceremony but sharing, no. I showed them later at home during the party'. (George)

\subsubsection{Privacy issue}

When sharing photos in public places, people are also concerned about their privacy. The level of privacy was an important factor in determining where, how and with whom 
to share photos. For the 'Kodak Culture' study group, privacy was the most important concern determining when and whether to share photos [16].

Participants talked about two different kinds of privacy; one was related to the content (subject) of photos. The decision about who can and cannot view a particular photo was based on the relationship between a viewer and a photo owner. The other kind of privacy was concerned with sharing photos in public places such as: pubs, bars, or restaurants where other people (e.g. strangers) in close proximity would be able to see shared photos. As seen in participants' comments they feel apprehensive when the content (subject) of photos is of private matter and there are chances that others (strangers) can view them.

'...If there is a party and there are lots of people around and there are people sitting with us that I don't really know them err...I might not want them to see my personal pictures ... because if I start with my friends, they [referring to strangers] might say: 'I want to see it' or something like that so instead of saying no, I prefer not to start the experience right from the beginning.' (Sami)

In bars or pubs, people tend to share photos on their handsets rather then using Bluetooth to transfer photos to their friends' phones. The physical layout of bars (e.g. more standing then sitting areas, closeness to other people moving around) does not promote a sense of privacy and Blue-jacking appeared to be a matter of concern for some participants:

'You need to switch on to Bluetooth, ... you don't want it all the time because of Blue-jacking and things like that'. (Lee)

\subsubsection{Private places}

Private places were described as places owned, used and accessed by individuals (e.g. houses, flats, and gardens).

Although participants described the home environment as a private place, within that they identified private and public space in relation to sharing. The former includes bedrooms and bathrooms whereas the later includes living rooms, kitchens and gardens.

'They [referring to friends] wouldn't necessarily go to the bathroom or to the bedroom to share the photos. No, these are places where usually don't invite people to share my pictures. These are more private.' (Juliet)

It emerged from the data that the mobile handset and Bluetooth were not the only means for sharing photos in the comfort of people's homes. People used external technology to display pictures such as TV, computer, or laptop. However, depending on technology utilised and its affordances sharing photos activity would happen in different spaces within a house. For instance, participants reported using laptop in a kitchen or a living room just because it was easy for them to move it around the house whereas sharing photos on TV was limited to its location, which commonly was in a living room.

'...Usually we sit in the living room and I'll bring my laptop and start showing the pictures ... if there are only a few friends and we sit in the kitchen, yeah ... but it's usually in the living room. It's a bigger place so we can sit comfortably around the laptop. ... In the kitchen I don't have that much space and living room is more social, I think, yeah.' (Sami)

People feel more relaxed and comfortable sharing photos in home environment. The physical attributes of home (e.g. comfortable sitting arrangement, space to move around freely, good lighting, low level of noise) promotes a more relaxed kind of sharing. There is no time pressure (e.g. closing hours) nor boundaries (e.g. where to sit), no strangers that might intrude in the sharing activity, which in turn makes people more at ease and enriches the sharing experience as participants reported:

'... In a house it's much easier ... because you have the TV and the computer and you can display it on the screen ... you can move around without bumping onto other people and it's nice, quite atmosphere unless there is a party going on so you'll have some noise but then you can go to a different room ... you can display your pictures on the computer or even you can pass your phone around without thinking that some strangers might look at your pictures without getting your permission'. (Nadia).

It was reported that people have more time to view different pictures from each other's collections, listen to stories behind them and finally Bluetooth the one they would like to have on their phones.

'... If you are just in a pub or somewhere crowded and just want to share a photo, you know, ... you just give the phone and the person will look at it but then usually, two or three weeks later when you are at the person's house having a barbeque, then you remember: 'oh, do you still have these photos?' and then you share them via Bluetooth because you are more relaxed'. (Lee)

\subsubsection{Work environment}

The workplace is seen as a professional environment and hence leisure and private related sharing is limited to sporadic occasions. At the same time, sharing at work is limited because often the relationship between people is on a professional, rather then informal or social basis.

'I'd only take photos of work if I was going to send them to people of work. I wouldn't ever let anybody at work to see my photos of anything ... it's strictly professional.'(Juliet)

It can be suggested that when sharing photos at work environment, the physical qualities are less significant than the cultural and social norms and regulations that are followed.

However, in some less formal work environments (e.g. leisure centre) people share photos with their colleagues, who are often their friends. Since the sharing happens between friends, the phone is passed from the owner of the phone to the viewer allowing pictures to be freely viewed.

'It depends what kind of work you do. I can do it at work ... when we finish [work] we show each other photos that we took before [pictures stored on their camera phones] ... it's between trainers and colleagues, yeah. (Nadia)

\section{HINDRANCES TO SHARING}

Although camera phones appeared to be a new medium for enjoyable social interaction, when it comes to photo sharing participants expressed their concern about issues that hinder their sharing experience. These are the level of privacy attached to a private as against a public collection of photos and the ways those photos could be organised and protected, and a lack of facilities to support sharing with multiple users within a large group of people. The following sections explore them in detail.

\subsection{Protection of privacy}

Withholding some private pictures from the view of others was an important factor when sharing experience is concerned. 
People decide which pictures to share with whom based on the value of a particular photo as well as their relationship with the viewer as discussed in section 4.2 and 4.3. However, the limitations of camera phones; that is not having facilities to create directory structure allowing the viewing of only selected folders and keeping private collections locked, often spoils the experience. People are concerned about others seeing photos that they consider to be private (which was illustrated in section 4.4.1.2); and that compromises their sharing experience.

Having such limitations, participants have to use alternative ways of protecting their privacy, one of which is to transfer private pictures from the camera phone onto a computer and delete them from the phone after the transfer.

To avoid this rather tedious activity new ways to support people organising and protecting their photos in anticipation of sharing behaviour (e.g. 'photos for my mum', 'photos for Bob', 'my photos') is required.

One solution to help for a better organisation and protection of photos might be the use of pre-defined lockable folders where a set of different folders (e.g. my last holiday, funny photos, 'my photos') could be created at any time and when a picture is taken a prompt given as to where to store the photo.

A finer-grained way of granting access to those different folders would mitigate some of the privacy protection concerns. For instance, the phone owner could 'open' a folder, allowing photos in the folder to be available for browsing, while other folders remain hidden and well protected.

\subsection{Sharing photos with multiple users}

Participants in this study reported that sharing with one person or a small group did not create any problems (either sharing the view on the phone, handing it over to the viewer or Bluetooth-ing to another phone), sharing with a group posed difficulties. Although, the most popular means of transfer is via Bluetooth it does not support people's requirements when transferring photos to multiple receivers; photos can be Bluetooth-ed only one at the time to a single receiver. The lack of facilities to support transfer of pictures to multiple users and the fact that a small camera phone screen allows pictures to be viewed simultaneously by only a small number of people often jeopardised their sharing experience.

A way to solve this problem could be a shared Bluetooth network connection such that the owner of the photo could access and send a specific photo to every person within this group simultaneously. This way of supporting group sharing - that is: easy distribution to multiple handsets might be appropriate in a public place (e.g. restaurant).

Novel uses of display or technology could alleviate the problem for larger groups, for instance by having a smoother transition to a large display surface, which in the context of private place (e.g. home) that would facilitate sharing better, or by allowing simultaneous viewing of the same pictures on several handsets (this links to the shared Bluetooth network idea).

\section{DISCUSSION AND CONCLUSION}

When discussing camera phones as technology supporting photo sharing between co-located participants, it is important to understand the role of the place where the sharing occurs, how and when people share photos, what determines who the photos are shared with and what influences their sharing experience.
The study results corroborated previous research findings detailing the different places that sharing of photos take place (private, public, and work environment). However, the interviews identified that people adapt different attributes of place to facilitate sharing activity, which changes depending who the photos are shared with. The suitability of pictures shared was one of the important issues raised by participants, which meant that all the pictures containing family events, holidays were viewed regardless of the quantity (often with duplication of themes) whereas pictures of friends were usually pre-selected by the owner sharing only a small selection of them.

The value of pictures was noted as an important factors determining when they were shared, who with, and how long they were kept in the photo collections. In the case of the social value of photos, the decision of a sharing circle was made at the time of taking them and the value was lost after everybody from the circle viewed them. Pictures with a personal value assigned to them were very evocative and meaningful to their owners and usually shared with only a selected circle of friends or loved ones. This study revealed that these types of photos are very precious; they are transferred between phones when the owner acquires a new handset, and their life span is unlimited.

The knowledge gained from this study provides a better understanding of how affordances of different places support the photo sharing activity; how social affordances determine the ways people share photos; how affordances of camera phones support different ways of sharing (e.g. 'on the spot', via Bluetooth or MMS); as well as how the value of photos determines how they are shared (e.g. sharing with friends, family or 'social interest group).

There are two design issues that are drawn from the study that may be used to improve the design of camera phones or other technology that supports photo sharing. The first relates to assigning a level of privacy to photo collections, thus allowing a distinction to be made between 'public' and 'private' areas of the collection. Such a facility would allow more selective ways of organising photographs and controlling how they are shared. The second issue is concerned with the lack of support for transferring to several users simultaneously. This issue was of the most importance when sharing within a large group of people.

Since camera phone screens limit the sharing to viewing pictures by one person at the time or just a small group, some means of supporting a bigger surface display and Bluetooth network would improve the sharing experience when a larger group of people is concerned.

Finally, although the study results touch on issues related to when it is accepted to take photos and when it is accepted to share them, a further study is required to explore the relationship between them in detail. Moreover, the cultural differences when sharing photos has not be fully investigated, which presents another opportunity for future work.

\section{ACKNOWLEDGMENTS}

We wish to thank all the participants who took part in our study.

\section{REFERENCES}

[1] Balanovic, M., Chu, L., \& Wolff, G. J. (2000). Storytelling with digital photographs. Paper presented at the SIGCHI 2000, (pp 564-571)

[2] Counts, S., \& Fellheimer, E. (2004). Supporting social presence through lightweight photo sharing on and 
off the desktop. Paper presented at the CHI, Vienna, Austria, (pp. 599-606)

[3] Chalfen, R. (1987). Snapshot version of life. Bowling Green, Ohio. Bowling Green State University Press.

[4] Ciolfi, L., Bannon, L. (2005). Space, place and design of technologically enhanced physical environments. In P. D. E. Turner (Ed.), Space, spatiality and technology: Springer, (pp.217-232)

[5] Crabtree, A., Rodden, T., \& Mariami, J. (2004). Collaborating Around Collections: Informing the Continued Development of Photoware. In Proceedings of the Conference on Computer Supported Cooperative Work (CSCW'04), November 6-10, 2004, Chicago, Illinois, USA, (pp. 396-405)

[6] Frohlich, D., Kuchinsky, A., Pering, C., Don, A., \& Ariss, S. (2002, 16-20 November). Requirements for photoware. Paper presented at the CSCW'02, New Orleans, Louisiana, USA, (pp. 166-175)

[7] Ito, M. (2003). A new set of social rules for a newly wireless society. Retrieved 28 July, 2006, from http://www.ojr.org/japan/wireless/1043770650.php

[8] Ito, M. (2004). Personal Portable Pedestrian: Lesson from Japanese Mobile Phone Use. Paper presented at the Paper presented at Mobile Communication and Social Change. The 24 International Conference on Mobile Communication. Seoul, Korea.

[9] Jones, Q., Grandhi, S.A., Whittaker, S., Chivakula, K., \& Terveen, L. (2004). Putting system into place: $A$ qualitative study of design requirements for locationaware community systems. Paper presented at the CSCW'04, (pp. 202-211)

[10] Kindberg, T., Spasojevic, M., Fleck, R., \& Sellen, A. (2005a). An in-depth study of camera phone use. Pervasive Computing, Vol. 4(No. 2), pp.42-50

[11] Kindberg, T., Spasojevic, M., Fleck, R., \& Sellen, A. (2005b). I Saw This and Thought of You: Some Social Uses of Camera Phones. CHI '05 extended abstracts on Human factors in computing systems. ACM Press: 1545-1548.

[12] Kirk, D. S., Sellen, A. J., Rother, C., \& Wood, K. R. (2006). Understanding Photowork. CHI 2006, Montreal, Quèbec, Canada, ACM, (pp.761-770)

[13] Kraut, R. E., Fussel, S.R., Brennan, S.E., \& Siegel, J. (2002). Understanding effects of proximity on collaboration: Implications for technologies to support remote collaborative work. In P. K. Hinds, S. (Ed.), Distributed work (pp. 137-162). Cambridge, MA: MIT Press.

[14] Licoppe, C., \& Heurtin, J.P. (2001). Managing one's availability to telephone communication through mobile phones: a French case study of the development dynamics of mobile phone use. Personal and Ubiquitous Computing, 5(2), 99-108.

[15] Mäkela, A. G., V., Tscheligi, M., \& Sefelin, R. (2000). Joking, storytelling, artsharing, expression affection: A field trial of how children and their social networks communication with digital images in leisure time. Conference on Human Factors in Computing Systems, (pp. 548-555)

[16] Miller, A. D., \& Edwards, W.K. (2007). Give and Take: A Study of Consumer Photo-Sharing Culture and Practice. In Proceedings of CHI 2007, April 28-May 3, 2007, San Jose, California, USA, (pp.347-356)

[17] Mulder, I., \& Steen, M. (2005). Mixed emotions, mixed methods: Conceptualising experience of we-centric context-aware adaptive mobile services. Paper presented at the Pervasive 2005. Presented at workshop on User Experience Design for Pervasive Computing. Munchen, Germany.

[18] Okabe, D. (2004). Emergent social practices, situations and relations through everyday camera phone use. Paper presented at the International Conference on Mobile Communication, Seoul, Korea.

[19] Okabe, D., \& Ito, M. (2003). "Camera phones changing the definition of picture-worthy." Japan Media Review. August 29, 2003.

[20] Okabe, D., \& Ito, M. (2005). Ketai and public transportation. In M. Ito, Okabe, D., \& Matuda, M. (Ed.), Personal, portable, pedestrian: Mobile phones in Japanese life. Cambridge: MIT, (pp. 205-218)

[21] Sack, R. D. (1997). Homo geographicus. A framework for action, awareness and moral concern. Baltimore: Johns Hopkins University Press.

[22] Scifo, B. (2004). The Domestication of Camera-Phone and MMS Communication: The Early Experience of Young Italians. Paper presented at the T-Mobile Conference, Hungary.

[23] Stelmaszewska, H., Fields, B., \& Blandford, A. (forthcoming). User experience of camera phones in social contexts. In Handbook of research on user interface design and evaluation for mobile technology.

[24] Stelmaszewska, H., Fields, B., \& Blandford, A. (2006). Camera phone use in social context. Paper presented at the HCI 2006, Queen Mary, University of London, UK.

[25] Strauss, A., \& Corbin, J. (1998). Basics of Qualitative Research. Techniques and Procedures for Developing Grounded Theory. Newbury Park: Sage.

[26] Strom, G. (2002). "Mobile Devices as Props in Daily Role Plying." Personal and Ubiquitous Computing 6: 307-310.

[27] Taylor, A., Harper, R. (2002). Age-old practices in the new world: a study of gift-giving between teenage mobile phone users. Proc. CHI 2002, ACM Press, (pp. 439-446)

[28] Van House, N. A., \& Davis, M. (2005). The Social Life of Cameraphone Images. In Proceedings of the Pervasive Image Capture and Sharing: New Social Practices and Implications for Technology Workshop (PICS 2005) at the Seventh International Conference on Ubiquitous Computing (UbiComp 2005).

[29] Van House, N., Davis, M., Ames, M., Finn, M., \& Viswanathan, V. (2005, 2-7 April). The Uses of Personal Networked Digital Imaging: An Empirical Study of Cameraphone Photos and Sharing. CHI '05 extended abstracts on Human factors in computing systems. ACM Press: 1853-1856.

[30] Van House, N. A. (2007). Flickr and Public ImageSharing: Distant Closeness and Photo Exhibition. CHI 2007, San Jose, California, USA, ACM.

[31] Weilenmann, A. Larsson, C. (2002). Local Uses and Sharing of Mobile Phones. Wireless World: Social and Interactional Aspects of the Mobile Age. B. Brown, Green, N. \& Harper, R. New York, Springer, (pp. 92-107)

[32] Whittaker, S., D. Frohlich and O. Daly-Jones (1994): 'Informal workplace communication: What is it like and how might we support it?' in: Proceedings of CHI 94, ACM, Boston, Massachusetts, pp. 131-137. 